\title{
Light Exposure and Shade Effects on Growth, Flowering, and Leaf Morphology of Spiraea alba Du Roi and Spiraea tomentosa $\mathrm{L}$.
}

\author{
Kelly M. Stanton \\ Department of Horticulture and Landscape Architecture, Purdue University, \\ West Lafayette, IN 47907
}

Sally S. Weeks

Department of Forestry and Natural Resources, Purdue University, West Lafayette, IN 47907

\author{
Michael N. Dana and Michael V. Mickelbart ${ }^{1}$ \\ Department of Horticulture and Landscape Architecture, Purdue University, \\ West Lafayette, IN 47907
}

Additional index words. meadowsweet, steeplebush, hardhack, native plants, shade tolerance

\begin{abstract}
Two native shrubs, Spiraea alba (meadowsweet) and Spiraea tomentosa (hardhack or steeplebush), have potential as landscape plants, but little is known about light requirements for these species. The performance of plants from four geographical seed sources of each species was evaluated in the field under six different light treatments: full sun; morning full sun; afternoon full sun; and $40 \%, 60 \%$, and $80 \%$ shade. Provenance differences did exist for height, flowering, and leaf greenness. Growth, flowering, and canopy density were greater in full sun and $40 \%$ shade and least in $80 \%$ shade. Both species responded to shade with increased individual leaf area and higher specific leaf area. Relative leaf greenness decreased with shade in $S$. tomentosa but did not change in $S$. alba. Plants grown in morning or afternoon shade were shorter and smaller and had fewer inflorescences than did the full-sun plants. These species can survive in deep shade, but based on growth and appearance, they are best suited to full sun or light shade in the landscape.
\end{abstract}

Light quantity and timing are often variable in urban and suburban landscapes (Kjelgren, 1995). Buildings often cast shadows to the north (in the northern hemisphere) and east and west sides of buildings provide only morning or afternoon sun, respectively. Trees can also cast considerable shade. Based on these varying light patterns, there is demand for shade-adapted flowering plants in urban landscapes (Schwartz, 1997).

The native shrubs $S$. alba (meadowsweet) and $S$. tomentosa (hardhack or steeplebush) grow to be 1 to $1.5 \mathrm{~m}$ tall with long-lasting terminal inflorescences present through most of the summer. Spiraea alba produces white flowers and $S$. tomentosa produces pink flowers. They are native to eastern North America and Canada and can be found growing from Canada

\footnotetext{
Received for publication 10 June 2010. Accepted for publication 11 Oct. 2010.

We thank JFNew and Mellow Marsh Farm for supplying plants. Rob Eddy and Daniel Hahn assisted with greenhouse plant growth and maintenance. Jay Young and Nathan Linder assisted with field setup and maintenance. Mike Gosney provided technical assistance and help with planting and measurements. Meghan Honerlaw assisted with statistical analyses.

${ }^{1}$ To whom reprint requests should be addressed; e-mail mickelbart@purdue.edu.
}

to the Gulf States (Smith, 2008; U.S. Department of Agriculture, 2007). Spiraea tomentosa was used in the landscape as early as 1736 (Symes, 1983). Today, however, both species are mainly used in habitat restoration. Many species within the genus Spiraea are valued for their form and flowering habits, and species not previously used in formal landscapes are being evaluated (Li and Zhang, 2008).

Light intensity can affect plant form, flowering, leaf size, and color in both herbaceous (Jeong et al., 2009; Vendrame et al., 2004) and woody species (Hampson et al., 1996). Shadetolerant plants have both morphological and physiological adaptations that allow them to adapt to low-light conditions (Boardman, 1977). Phenotypic response to light can vary within a species, suggesting that selection may allow for development of cultivars with enhanced shade tolerance (Kitajima et al., 2006; Siemann and Rogers, 2001).

Spiraea alba and S. tomentosa are usually found growing in full sun and populations of these species are not maintained when shaded after forest regeneration (Darbyshire, 2003; Flaccus, 1959). This suggests both species are adapted to full sun. However, there are no published reports documenting the degree of shade tolerance of these species. Furthermore, response to light can vary among genotypes within a species (Jeong et al., 2009; Johnson and Cartwright, 2005). Therefore, we felt it was important to base general recommendations on evaluations using a wide range of germplasm rather than a single genotype. Growth and flowering of $S$. alba and $S$. tomentosa plants produced from seed of different geographical origin under several light regimens were evaluated to determine landscape potential of these plants under varied light conditions. Potential shade-adaptation mechanisms in both species were investigated.

\section{Materials and Methods}

Plant material and field plots. Seeds from four $S$. alba and four $S$. tomentosa seed sources were germinated and grown in $40-\mathrm{cm}^{3}$ plugs at Purdue University or at collaborating nurseries (Table 1). Plants were transplanted to 2-L containers in Mar. 2008. Each seed source was given a unique identifier: the first letter indicates species and the next two letters are the state or province abbreviation of each seed source. On 16 July 2008, plants were planted at the Meigs Farm of the Throckmorton Purdue Agricultural Center in Tippecanoe County, IN (lat. $40.29^{\circ} \mathrm{N}$, long. $86.88^{\circ} \mathrm{W}$ ). The soil type is Drummer (silty clay loam) (Soil Conservation Service, 1998) with a $\mathrm{pH}$ of 6.9.

Plants were grown under one of six light treatments: full sun; morning full sun; afternoon full sun; and $40 \%, 60 \%$, and $80 \%$ shade. Each plot was $7.3 \times 1.5 \mathrm{~m}$. Fences $(1.5 \mathrm{~m}$ tall $)$ were built of chipboard on the east or west side of the afternoon or morning sun plots, respectively. To keep plants in shade as midday approached, 0.3-m chipboard overhangs were attached perpendicularly to the top of the fence. Shadecloth canopies were constructed over plots to give light intensity levels of $40 \%$, $60 \%$, or $80 \%$ shade. Each canopy was formed by spreading shadecloth (DeWitt knitted shadecloth, Sikeston, MO) over a row of seven $1.5 \mathrm{~m}$ tall and $1.8 \mathrm{~m}$ wide arches. Each arch was made by pounding two $0.5-\mathrm{m}$ lengths of $1.27 \mathrm{~cm}$ EMT conduit into the ground, sliding a $1.8-\mathrm{m}$ length of $1.9 \mathrm{~cm}$ polyvinyl chloride (PVC) pipe over each piece of conduit, and then connecting PVC pipes at the apex with a $90^{\circ}$ elbow connector. The plots were irrigated with drip tape as required to avoid water stress.

Design and analysis. The experiment was laid out in a split-plot design. Six light treatments were the main plots with genotype (both $S$. alba and $S$. tomentosa) randomized within each plot. Each set of six light treatment plots was randomized within one of 16 blocks. There was one replication plant per block. Therefore, there were 16 replicates for each genotype $x$ treatment level. Plant height at planting was $27.6 \pm 0.7$ and $25.3 \pm 0.5 \mathrm{~cm}$ for $S$. alba and $S$. tomentosa, respectively, with no significant differences among ecotypes of either species. Some of the QC seed source $S$. tomentosa did not grow well in Spring 2008. Only plants that were growing vigorously in Spring 2008 were used, which resulted in a shortage of T-QC plants. For this reason, this seed source was not planted in morning and evening sun plots. Data were analyzed with SAS 9.1 (SAS Institute Inc., Cary, NC) using PROC GLM. Transformations 
of measured variables were used as needed to correct for non-constant variance and lack of normality. Transformations used are given in tables where data are presented. All values presented are averages of untransformed data.

Measurements. All measurements were conducted in 2009. Light intensities in each treatment were measured throughout the season with a handheld light meter (LI-250A; LI-COR, Lincoln, NE). Readings were taken at midday and 3 and $6 \mathrm{~h}$ before and after midday (Fig. 1). The light sensor was held $1 \mathrm{~m}$ above soil level in each plot. We present representative data from one cloud-free day, 31 May (Fig. 1).

On 27 June, plant height was determined as the vertical distance from the ground to the highest portion of the plant. Average width of each plant was calculated as the mean of north-south and east-west width. Canopy density was estimated based on a visual rating system to quantify the amount of space among stems when viewed from the side with no canopy (full light penetration) rated a 0 and fully closed (no light penetration) rated a 10.

Post-anthesis inflorescences remained on fore, inflorescences produced by each plant were counted on 13 and 14 Sept. plants throughout the growing season. There-

A SPAD 502 meter (Minolta, Osaka, Japan) was used to determine relative leaf greenness (Netto et al., 2005) on 1 July. The mean of three measurements taken on a recently matured, fully expanded leaf was recorded for each plant.

Three recently matured, fully expanded leaves were removed from each plant in early July and photographed. Leaf area (LA) was determined from the digital image using Image J 1.38x software (National Institutes of Health, Bethesda, MD). Leaves were then dried to a constant weight at $70{ }^{\circ} \mathrm{C}$ to obtain leaf dry weight (DW). Specific leaf area (SLA) was calculated as SLA $=$ LA/DW. Aboveground biomass was collected and dried to a constant weight to obtain $\mathrm{DW}$ at the end of the growing season.

\section{Results}

Fences and shading structures provided excellent treatment differences under which to evaluate these species (Fig. 1). Fences on the east and west sides of plants resulted in direct light measurements at plant height of $\approx 100 \mu \mathrm{mol} \cdot \mathrm{m}^{-2} \cdot \mathrm{s}^{-1}$ before and after noon, respectively, but allowed for full sun after and before noon, respectively. Shadecloth structures provided consistent reductions in light levels throughout the day.

Table 1. Seed sources of $S$. alba and $S$. tomentosa used in this study to determine relative growth and flowering under different light conditions. ${ }^{2}$

\begin{tabular}{lllll}
\hline ID & \multicolumn{1}{c}{ Species } & \multicolumn{1}{c}{ Supplier } & Accession & \multicolumn{1}{c}{ Seed collection site } \\
\hline A-ON & S. alba & NPGS & PI 607440 & Ontario, Canada \\
A-MI & S. alba & NPGS & PI 564841 & Michigan, Kent Co. \\
A-AB & S. alba & NPGS & PI 636387 & Alberta, Leduc Co. Canada \\
A-IN & S. alba & JFNew & & Indiana, St. Joseph Co. \\
T-MI & S. tomentosa & NPGS & PI 649743 & Michigan, Wayne Co. \\
T-QC & S. tomentosa & NPGS & PI 578120 & Quebec, Bolton Co. Canada \\
T-IN & S. tomentosa & JFNew & & Indiana, St. Joseph Co. \\
T-NC & S. tomentosa & Mellow Marsh Farm & & North Carolina, Forsyth Co. \\
\hline
\end{tabular}

${ }^{2} \mathrm{ID}$ (used throughout text) given to each seed source indicates species $(\mathrm{A}=S$. alba $; \mathrm{T}=S$. tomentos $a)$ and state or province abbreviation of each seed source $(\mathrm{ON}=$ Ontario; $\mathrm{MI}=$ Michigan; $\mathrm{AB}=$ Alberta; $\mathrm{IN}=$ Indiana; $\mathrm{QC}=$ Quebec; and $\mathrm{NC}=$ North Carolina). Plants were supplied as seed from the National Plant Germplasm System (NPGS) or as plugs from two commercial nurseries (JFNew and Mellow Marsh Farm). Accession number refers to the NPGS number for accessions documented in the NPGS Germplasm Resources Information Network (GRIN). State or province and county of the seed collection site where seed was originally collected is indicated.

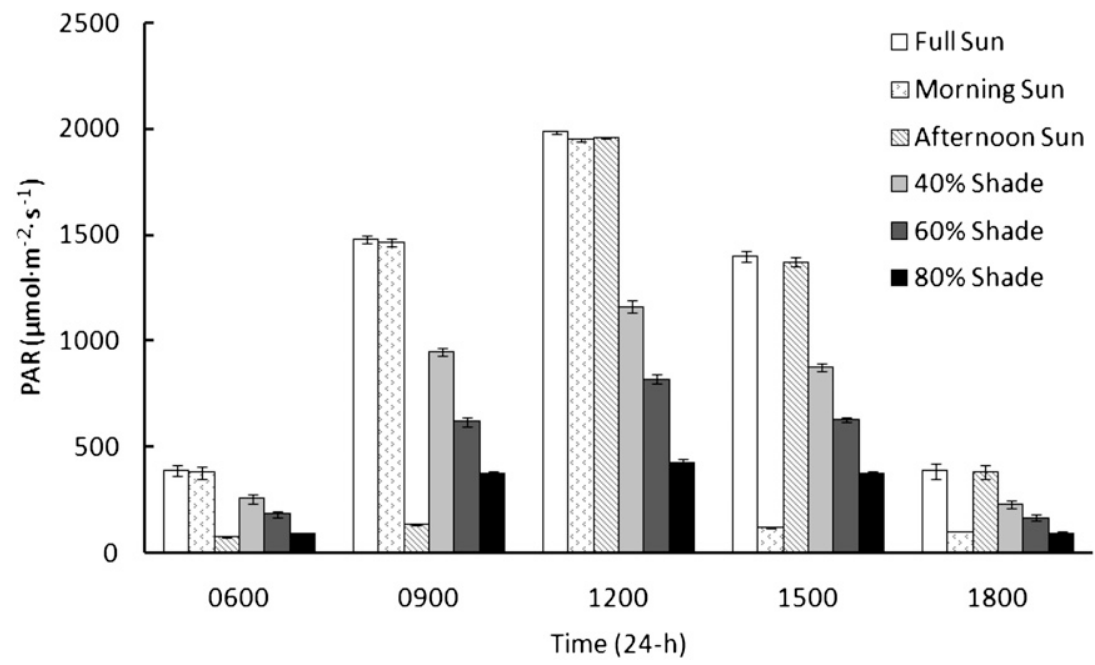

Fig. 1. Light intensity in six light treatments at midday and 3 and $6 \mathrm{~h}$ before and after midday of 31 May 2009. Columns represent the mean of 16 blocks; error bars represent SE.
Plant height was not different among plants at planting (data not shown). Therefore, only final plant height at the end of June is presented. There was very little difference in height as shading increased in $S$. alba plants grown from different seed sources, although plants grown from IN and ON seed sources were shorter in $80 \%$ shade (Table 2). Among $S$. tomentosa plants, T-IN and T-QC were shorter in $60 \%$ and $80 \%$ shade, whereas T-MI and T-NC plants were only shorter when grown under $80 \%$ shade. With the exception of one seed source, $S$. tomentosa plants grown with only afternoon or morning sun were smaller than plants grown in full sun.

There was no seed source-by-species interaction for biomass, canopy width, canopy density, or SLA. Therefore, mean values overall seed sources are presented (Table 3). Plant width did not vary among seed sources, and in both species, only morning sun reduced plant width (Table 3 ). In both species, $40 \%$ shade did not result in a reduction in biomass. However, biomass was reduced slightly by $60 \%$ shade and half-day shade, and $80 \%$ shade resulted in plants less than half the size of fullsun plants in both species (Table 3).

Newly produced shoots of plants grown in morning and afternoon sun treatments had a tendency to grow away from the fence providing shade. Under these conditions, new shoots tended to grow together and thus, canopy density of these plants was high (Table 3 ). Canopy density of both species was similar among full sun and moderately shaded plants, but decreased substantially as shading increased.

Spiraea alba began blooming in mid-June, 2 to 3 weeks before $S$. tomentosa. Plants from Canadian seed sources of both species began blooming a few weeks earlier than did plants from more southern seed sources (Stanton, personal observation). On average, full sun 1-year-old $S$. alba plants produced just over six inflorescences per plant (Table 4). NC $S$. tomentosa produced the largest number of inflorescences. Both species produced more inflorescences in full sun or moderate shade. In all cases, limiting full sun to afternoon or morning resulted in reduced flowering.

In $S$. alba, plants grown under half-day sun had larger leaves than did full sun plants (Table 3). Individual LA was also larger in shaded plants. Plants under $80 \%$ shade had leaves that were 1.5 times larger than leaves in full sun. In $S$. tomentosa, LA was not different in plants exposed to full or half-day sun. Leaves of shaded plants were slightly larger than those on full-sun plants, but differences in LA were not as great in $S$. tomentosa as they were in $S$. alba. In all plants of both species, SLA increased with shading and half-day light (Table 3 ). Specific leaf area increased by $\approx 15 \%, 25 \%$, and $60 \%$ with $40 \%, 60 \%$, and $80 \%$ shade, respectively, in both species. Morning or afternoon sun both resulted in SLA increases of $10 \%$ and $22 \%$ in $S$. alba and $S$. tomentosa, respectively.

When grown in full sun, $\mathrm{A}-\mathrm{AB}$ and T-QC plants had the darkest green leaves within 
their respective species (Table 5). There was no interaction between light treatment and seed source in $S$. tomentosa $(P=0.3843)$, but there was in $S$. alba $(P=0.0096)$. Changes in relative leaf greenness in response to light treatment varied among plants from different seed sources within a species. Leaf color of A-MI was similar under all treatments. In $\mathrm{A}-\mathrm{AB}$ and $\mathrm{A}-\mathrm{ON}, 40 \%$ shade resulted in darker green leaves, whereas higher shade levels resulted in similar leaf color to control plants. In S. tomentosa, shading resulted in lighter green leaves in plants grown from all seed sources. There were no consistent patterns between AM or PM sun treatments and SPAD values in either species, although in most cases, limiting plants to a half-day of full sun did not result in a change in leaf color. When it did, leaves were darker green in $S$. alba (A-IN and A-ON) but lighter green in S. tomentosa (T-IN and T-NC).

Table 2. Height (cm) of $S$. alba and $S$. tomentosa in late June 2009 grown under full sun; only morning (AM sun) or afternoon (PM sun) full sun; or under shadecloth providing $40 \%, 60 \%$, or $80 \%$ shade in Tippecanoe Co., IN $(\mathrm{n}=16)^{\mathrm{z}}$

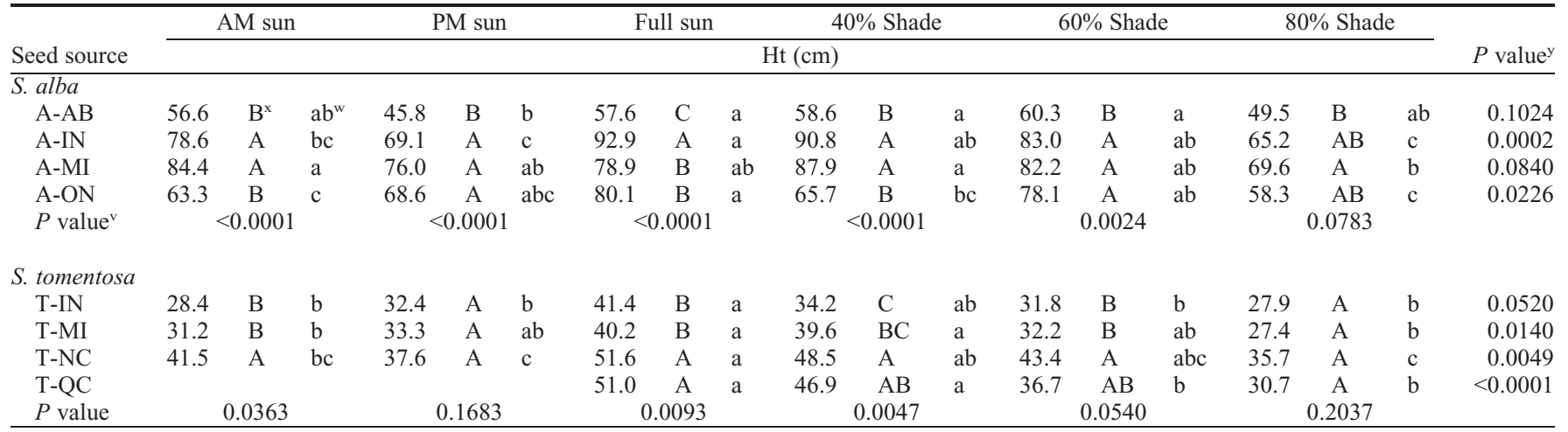

${ }^{\mathrm{z}}$ Seed sources from which plants were grown are described in Table 1

${ }^{\mathrm{y}}$ Significance of treatment differences [analysis of variance (ANOVA)] within a species and seed source.

${ }^{x}$ Mean separation among seed sources within a species and treatment indicated by uppercase letters using Tukey's honestly significant difference test $(P \leq 0.05)$.

"Mean separation among treatments within a species and seed source indicated by lowercase letters using Tukey's honestly significant difference test $(P \leq 0.05)$.

${ }^{v}$ Significance of seed source differences (ANOVA) within a species and treatment.

Table 3. Late June 2009 measurements of biomass, width, canopy density, leaf area (LA), and specific leaf area (SLA) of S. alba and S. tomentosa plants from different seed sources grown under full sun; only morning (AM sun) or afternoon (PM sun) full sun; or under shadecloth providing $40 \%, 60 \%$, or $80 \%$ shade in Tippecanoe Co., IN ( $\mathrm{n}=64$ for $S$. alba; $\mathrm{n}=48$ for $S$. tomentosa). ${ }^{\mathrm{z}}$

\begin{tabular}{|c|c|c|c|c|c|c|c|c|c|c|}
\hline \multirow[b]{2}{*}{ Treatment } & \multicolumn{5}{|c|}{ S. alba } & \multicolumn{5}{|c|}{ S. tomentosa } \\
\hline & Biomass $^{y}$ (g) & Width $(\mathrm{cm})$ & Canopy density & $\mathrm{LA}^{\mathrm{w}}\left(\mathrm{cm}^{2}\right)$ & $\operatorname{SLA}^{\mathrm{w}}\left(\mathrm{cm}^{2} \cdot \mathrm{g}^{-1}\right)$ & Biomass (g) & Width $(\mathrm{cm})$ & Canopy density & LA $\left(\mathrm{cm}^{2}\right)$ & SLA $\left(\mathrm{cm}^{2} \cdot \mathrm{g}^{-1}\right)$ \\
\hline PM sun & $41 \mathrm{~b}$ & $38.5 \mathrm{~b}$ & $7.2 \mathrm{a}$ & $3.47 \mathrm{c}$ & $154 \mathrm{c}$ & $27 \mathrm{~b}$ & $27.5 \mathrm{bc}$ & $7.2 \mathrm{a}$ & $5.72 \mathrm{bc}$ & $149 \mathrm{~b}$ \\
\hline Full sun & $54 \mathrm{a}$ & $40.1 \mathrm{ab}$ & $6.7 \mathrm{bc}$ & $2.98 \mathrm{~d}$ & $141 \mathrm{~d}$ & $45 \mathrm{a}$ & $29.9 \mathrm{ab}$ & $6.7 \mathrm{bc}$ & $5.08 \mathrm{c}$ & $122 \mathrm{~d}$ \\
\hline $60 \%$ shade & $41 \mathrm{~b}$ & $39.7 \mathrm{ab}$ & $6.1 \mathrm{~cd}$ & $3.88 \mathrm{~b}$ & $173 \mathrm{~b}$ & $31 \mathrm{~b}$ & $28.6 \mathrm{ab}$ & $6.1 \mathrm{~cd}$ & $5.95 \mathrm{ab}$ & $152 \mathrm{~b}$ \\
\hline $80 \%$ shade & $25 \mathrm{c}$ & $38.6 \mathrm{~b}$ & $5.8 \mathrm{~d}$ & $4.60 \mathrm{a}$ & $221 \mathrm{a}$ & $16 \mathrm{c}$ & $27.7 \mathrm{bc}$ & $5.5 \mathrm{~d}$ & $6.18 \mathrm{a}$ & $206 \mathrm{a}$ \\
\hline$P$ value $^{\mathrm{u}}$ & $<0.0001$ & $<0.0001$ & $<0.0001$ & $<0.0001$ & $<0.0001$ & $<0.0001$ & 0.0023 & $<0.0001$ & 0.0003 & $<0.0001$ \\
\hline
\end{tabular}

${ }^{\mathrm{z}}$ Values are pooled averages for all seed sources within each species. Seed sources from which plants were grown are described in Table 1.

${ }^{\mathrm{y}}$ Biomass was transformed $(\sqrt{ } \mathrm{Y})$ to obtain constant variance.

${ }^{\mathrm{x}}$ Canopy density values were transformed $\left(\mathrm{Y}^{2}\right)$ before analysis to obtain normally distributed data with constant variance.

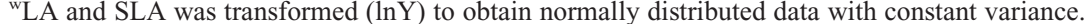

${ }^{\vee}$ Mean separation among treatments indicated by lowercase letters using Tukey's honestly significant difference test $(P \leq 0.05)$.

uSignificance of treatment differences (analysis of variance).

Table 4. Number of inflorescences produced in 2009 by S. alba and S. tomentosa plants from different seed sources grown under full sun; only morning (AM sun) or afternoon (PM sun) full sun; or under shadecloth providing $40 \%, 60 \%$, or $80 \%$ shade in Tippecanoe Co., IN $(\mathrm{n}=16){ }^{\mathrm{z}}$

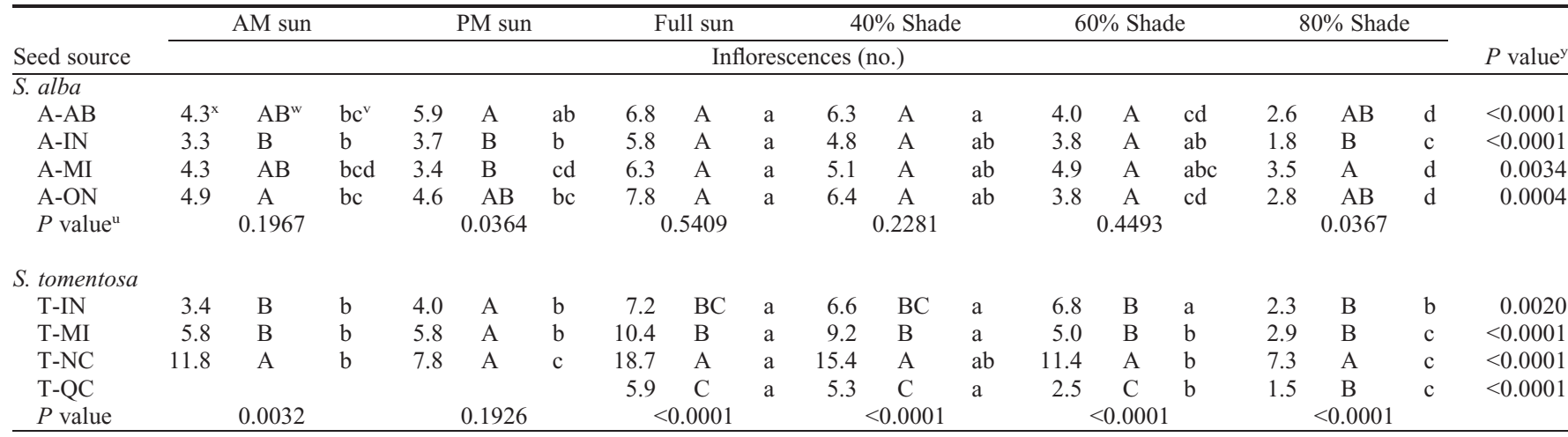

${ }^{\mathrm{z}}$ Seed sources from which plants were grown are described in Table 1.

${ }^{y}$ Significance of treatment differences [analysis of variance (ANOVA)] within a species and seed source.

${ }^{\mathrm{x}}$ Data were transformed $(\sqrt{ } \mathrm{Y})$ to correct for normality and constant variance.

${ }^{\text {w} M e a n ~ s e p a r a t i o n ~ a m o n g ~ s e e d ~ s o u r c e s ~ w i t h i n ~ a ~ s p e c i e s ~ a n d ~ t r e a t m e n t ~ i n d i c a t e d ~ b y ~ u p p e r c a s e ~ l e t t e r s ~ u s i n g ~ T u k e y ' s ~ h o n e s t l y ~ s i g n i f i c a n t ~ d i f f e r e n c e ~ t e s t ~}(P \leq 0.05)$.

'Mean separation among treatments within a species and seed source indicated by lowercase letters using Tukey's honestly significant difference test $(P \leq 0.05)$.

"Significance of seed source differences (ANOVA) within a species and treatment. 
Table 5. Leaf greenness (SPAD) of S. alba and S. tomentosa plants in early July 2009 from different seed sources grown under full sun; only morning (AM sun) or afternoon (PM sun) full sun; or under shadecloth providing $40 \%, 60 \%$, or $80 \%$ shade in Tippecanoe Co., IN $(\mathrm{n}=16){ }^{\mathrm{z}}$

\begin{tabular}{|c|c|c|c|c|c|c|c|c|c|c|c|c|c|c|c|c|c|c|c|}
\hline \multirow{3}{*}{$\begin{array}{l}\text { Seed source } \\
\text { S. alba }\end{array}$} & \multicolumn{3}{|c|}{ AM sun } & \multicolumn{3}{|c|}{ PM sun } & \multicolumn{3}{|c|}{ Full sun } & \multicolumn{3}{|c|}{$40 \%$ Shade } & \multicolumn{3}{|c|}{$60 \%$ Shade } & \multicolumn{3}{|c|}{$80 \%$ Shade } & \multirow[b]{2}{*}{$P$ value $^{\mathrm{x}}$} \\
\hline & \multicolumn{18}{|c|}{ Leaf greenness (SPAD) ${ }^{y}$} & \\
\hline & & & & & & & & & & & & & & & & & & & \\
\hline A-AB & 39.4 & $\mathrm{~A}^{\mathrm{w}}$ & $b^{v}$ & 37.1 & A & $\mathrm{b}$ & 37.2 & A & $\mathrm{b}$ & 45.5 & A & a & 38.2 & A & $\mathrm{b}$ & 36.0 & A & $\mathrm{b}$ & $<0.0001$ \\
\hline $\mathrm{A}-\mathrm{ON}$ & 32.8 & $\mathrm{~B}$ & $\mathrm{bc}$ & 36.4 & $\mathrm{AB}$ & $\mathrm{a}$ & 31.7 & B & $\mathrm{c}$ & 35.8 & $\mathrm{~B}$ & $a b$ & 31.3 & B & $\mathrm{c}$ & 32.7 & B & $\mathrm{bc}$ & 0.0036 \\
\hline$P$ value $^{\mathrm{u}}$ & \multicolumn{3}{|c|}{$<0.0001$} & \multicolumn{3}{|c|}{0.0424} & \multicolumn{3}{|c|}{$<0.0001$} & \multicolumn{3}{|c|}{$<0.0001$} & \multicolumn{3}{|c|}{$<0.0001$} & \multicolumn{3}{|c|}{0.0108} & \\
\hline T-MI & 34.0 & A & $a b$ & 36.8 & A & $\mathrm{a}$ & 37.0 & $\mathrm{C}$ & $\mathrm{a}$ & 36.2 & $\mathrm{BC}$ & $a b$ & 32.8 & $\mathrm{AB}$ & $\mathrm{bc}$ & 29.0 & B & $\mathrm{c}$ & 0.0006 \\
\hline $\mathrm{T}-\mathrm{NC}$ & 35.3 & $\mathrm{~A}$ & $a b$ & 32.4 & $\mathrm{~B}$ & $\mathrm{bc}$ & 37.5 & $\mathrm{BC}$ & $\mathrm{a}$ & 32.9 & $\mathrm{C}$ & $\mathrm{bc}$ & 30.5 & B & $\mathrm{dc}$ & 27.4 & B & d & $<0.0001$ \\
\hline T-QC & & & & & & & 48.6 & A & a & 41.4 & A & $\mathrm{b}$ & 36.0 & A & $\mathrm{c}$ & 36.9 & A & $\mathrm{c}$ & $<0.0001$ \\
\hline$P$ value & \multicolumn{3}{|c|}{0.8456} & \multicolumn{3}{|c|}{0.0059} & \multicolumn{3}{|c|}{$<0.0001$} & \multicolumn{3}{|c|}{$<0.0001$} & \multicolumn{3}{|c|}{0.0096} & \multicolumn{3}{|c|}{0.0004} & \\
\hline
\end{tabular}

${ }^{2}$ Seed sources from which plants were grown are described in Table 1.

${ }^{\mathrm{y}}$ Data were transformed by $\mathrm{Y}^{1.5}$ to obtain normally distributed data with constant variance. Interactions between seed source and light treatment were nonsignificant for both species.

${ }^{x}$ Significance of treatment differences [analysis of variance (ANOVA)].

"Seed sources within each treatment are significantly different if they are given different capital letters (Tukey $P \leq 0.05$ ).

vTreatments are significantly different for a given seed source if they are assigned different lower case letters (Tukey $P \leq 0.05$ ).

"Significance of seed source differences (ANOVA).

\section{Discussion}

This study was not designed to quantify the genetic variability for shade tolerance in this species nor was it designed to calculate heritability of traits. However, species with a wide range of native habitats can differ for adaptation to shade (Johnson and Cartwright, 2005), and these genetic differences, if observed, could be exploited when developing cultivars for managed landscapes. More importantly, when evaluating new species for landscape potential, it is important that the description of horticultural traits is not based on a single accession. In this study, there were seed source-by-treatment interactions (Tables 2, 4, and 5). Overall, however, light responses of plants from different seed sources were very similar. For example, although $S$. alba grown from different seed sources exhibited statistically significant differences in height at $80 \%$ shade levels, height was $70 \%$ to $88 \%$ of full sun height in all seed sources (Table 2).

Shade-tolerant plants typically have low photosynthetic rates but have the ability to efficiently capture and use light energy, usually through increased chlorophyll concentration (Boardman, 1977) or increased SLA (Reich et al., 1998). Relative leaf greenness (used as a proxy for relative chlorophyll concentration), based on SPAD measurements, did not increase in $S$. tomentosa plants in response to shade (Table 5). The response of $S$. alba was more varied among plants from different seed sources, and two $40 \%$ shade treatments did have darker green leaves than full-sun plants. The primary adaptation of these two species to low light levels appears to be through increased SLA. However, there was no evidence for differences in plasticity among the genotypes in this study. Both $S$. alba and $S$. tomentosa had thinner, larger leaves in shade, and all plants of all species responded to either constant or half-day shading with increased SLA (Table 3). However, any adaptations these plants use to adapt to shade still resulted in reduced biomass in the $60 \%$ or $80 \%$ shade treatments (Table 3 ).

Canopy growth and form in a given species is often different in sun and shade habitats (Johnson and Cartwright, 2005). Decreased branching density under shade occurs in other species such as sugar maple (Acer saccharum) (Steingraeber et al., 1979) and may be an adaptation that allows for greater light use efficiency within the canopy (Smith, 1982). In this study, canopy density was lower in shade (Table 3). However, there was no seed source-by-light interaction for canopy density, suggesting plants from all seed sources responded similarly. Furthermore, it is difficult to state conclusively whether changes in canopy density were an adaptive response that would allow these plants to continue to grow in shade. Given the fact that all growth parameters were reduced in shade, it seems reasonable to speculate that these species do not adapt well to shaded conditions.

Plants grown from more northern seed sources $(\mathrm{A}-\mathrm{AB}, \mathrm{A}-\mathrm{ON}$, and $\mathrm{T}-\mathrm{QC})$ were first to flower and first to begin losing leaves in the fall. Timing of fruiting and leaf fall is largely determined by genetic adaptation of a given plant to photoperiod (Kramer, 1936; Pounders et al., 2010). Although early flowering could be an advantage in a landscape plant, early leaf fall of plants from northern seed sources resulted in less attractive plants in September than those from Michigan, Indiana, and North Carolina. During summer, however, the shorter, more branched form of A-AB and A$\mathrm{ON}$ hid bare lower stems that were visible on taller, more erect $S$. alba plants from southern seed sources (Stanton, personal observation).

In this study, both $S$. tomentosa and $S$. alba were largest and produced the most inflorescences in full sun and light shade and therefore are recommended for these conditions in the landscape. In deep shade, they were smaller (Tables 2 and 3), had decreased branching density (Table 3 ), and bore fewer flowers (Table 4). This was true for all seed sources, although there was variation in size, flowering, and form.

\section{Literature Cited}

Boardman, N.K. 1977. Comparative photosynthesis of sun and shade plants. Annu. Rev. Plant Physiol. 28:355-377.

Darbyshire, S.J. 2003. Inventory of Canadian agricultural weeds. Agriculture and Agri-Food Canada, Ottawa, Canada.

Flaccus, E. 1959. Revegetation of landslides in the White Mountains of New Hampshire. Ecol. 40:692-703.

Hampson, C.R., A.N. Azarenko, and J.R. Potter. 1996. Photosynthetic rate, flowering, and yield component alteration in hazelnut in response to different light environments. J. Amer. Soc. Hort. Sci. 121:1103-1111.

Jeong, K.Y., C.C. Pasian, M. McMahon, and D. Tay. 2009. Growth of six Begonia species under shading. Open Hort. J. 2:22-28.

Johnson, G.R. and C. Cartwright. 2005. Genotype $\times$ shade effects for western hemlock. Can. J. For. Res. 35:1496-1501.

Kitajima, K., A.M. Fox, T. Sato, and D. Nagamatsu. 2006. Cultivar selection prior to introduction may increase invasiveness: Evidence from $\mathrm{Ardi}$ sia crenata. Biol. Invasions 8:1471-1482.

Kjelgren, R. 1995. Variable urban irradiance and shade acclimation in Norway maple street trees. J. Arbor. 21:145-149.

Kramer, P.J. 1936. Effects of variation in length of day on growth and dormancy of trees. Plant Physiol. 11:127-137.

Li, J. and Q. Zhang. 2008. Studies on resources of Spiraea in north China and application in gardens. Acta Hort. 769:415-420.

Netto, A.T., E. Campostrini, J.G. de Oliveira, and R.E. Bressan-Smith. 2005. Photosynthetic pigments, nitrogen, chlorophyll $a$ fluorescence and SPAD-502 readings in coffee leaves. Sci. Hort. 104:199-209.

Pounders, C.T., E.K. Blythe, D.C. Fare, G.W Knox, and J.L. Sibley. 2010. Crapemyrtle genotype $\times$ environment interactions, and trait stability for plant height, leaf-out, and flowering. HortScience 45:198-207.

Reich, P.B., M.G. Tjoelker, M.B. Walters, D. Vanderklein, and C. Buschena. 1998. Close association of RGR, leaf and root morphology, 
seed mass and shade tolerance in seedlings of nine boreal tree species grown in high and low light. Funct. Ecol. 12:327-338.

Schwartz, B. 1997. Filling the shadows with light. American Nurseryman 185(8):44-51.

Siemann, E. and W.E. Rogers. 2001. Genetic differences in growth of an invasive tree species. Ecol. Lett. 4:514-518.

Smith, H. 1982. Light quality, photoperception, and plant strategy. Annu. Rev. Plant Physiol. 33:481518.
Smith, W. 2008. Trees and shrubs of Minnesota. Univ. Minnesota Press, Minneapolis, MN.

Soil Conservation Service. 1998. Soil survey of Tippecanoe County, Indiana. U.S. Gov. Print. Office, Washington, DC.

Steingraeber, D.A., L.J. Kascht, and D.H. Franck. 1979. Variation of shoot morphology and bifurcation ratio in sugar maple (Acer saccharum) saplings. Amer. J. Bot. 66:441445 .
Symes, M. 1983. Charles Hamilton's plantings at Painshill. Gard. Hist. 11:112-124.

U.S. Department of Agriculture. 2007. Spiraea L. The PLANTS Database. National Plant Data Center, Baton Rouge, LA. 7 Nov. 2007. <http:// plants.usda.gov/java/profile? symbol=SPIRA $>$.

Vendrame, W., K.K. Moore, and T.K. Broschat. 2004. Interaction of light intensity and controlled-release fertilization rate on growth and flowering of two New Guinea impatiens cultivars. HortTechnology 14:491-495. 